\title{
PROFESSIONAL ETHICS AND A CALL FOR PHILOSOPHICAL LITERACY
}

\author{
Pre-Print copy \\ Published in Think 54, Vol. 19 (Spring, 2020) 37-47 \\ A Journal of The Royal Institute of Philosophy \\ DOI: https://doi.org/10.1017/S1477175619000290
}

Andrew Knight

It could be argued that there is now a crisis of confidence in the professions. Although many professionals individually undertake their roles with care and diligence, there have been so many systematic failures involving professionals across a range of sectors, both in the UK and globally, that the special status enjoyed by the professions is being widely questioned. In this article, I argue that recent cases are symptomatic of a lack of ethical reasoning in professional practice, yet professions enjoy an elevated status based on claims that ethics, typically communicated in codes of conduct, are central to their purpose. I argue that to help solve this crisis, philosophical literacy needs to be promoted in school, initial professional education and continuing professional development. Passing tests to superficially demonstrate an understanding of a code is quite different from reasoning through practical dilemmas in the professional workplace with judgements informed by philosophical ideas.

\section{The Context}

Time and time again, questions are being asked by a range of stakeholders as to why those in charge at the time of organizational failure, typically members of professional bodies, did not act to uphold the professional standards they claim for their profession. To underpin these claims, I will start with the recent case of the collapse of Carillion early in 2018.

Carillion was a large company specializing in construction and facilities management. At the time of its downfall it had over 40,000 employees and provided a range of services ranging from school meals to defence accommodation. The company left a pension liability of $£ 2.6$ billion and massive debts to its supply chain, with the taxpayer required to pick up a least $£ 150$ million to keep services running for the public sector in addition to pension liabilities (HC 2018: 3). Of course, one may argue that in a market economy businesses fail; however, the scale of failure was caused not by economic conditions, but by the 'relent-less dash for cash' strategy of Carillion's board (ibid. 3). Moreover, the failure of professional accountancy firms, who were there to check standards of governance, is nothing short of astonishing to most people.

The findings of a House of Commons committee were clear in its condemnation of those running and monitoring Carillion. The committee described the 'rotten corporate culture' and accounts that 
were 'systematically manipulated to make optimistic assessments of revenue, in defiance of internal controls' (HC 2018: 4). The whole purpose of the auditing profession is to provide an objective and independent assessment of the accounts of organizations. Nevertheless, the committee stated that KPMG, the auditors for nineteen years, signed off 'directors' increasingly fantastical figures' (ibid. 4) and concluded 'there is a danger of a crisis of confidence in the audit profession. KPMG's audits of Carillion were not isolated failures, but symptomatic of a market which works for the Big Four firms but fails the wider economy' (ibid. 5). These words have been quoted since it is hard to imagine how much stronger a government report could be in condemning a profession. While many smaller businesses have been left with unpaid debts, thousands of individuals face personal uncertainly as they hunt to find new work. But the crisis in trust is not limited to the professions engaged in big business: the healthcare professions provide many examples of recent failures.

Cases like that of Dr Harold Shipman, the General Practitioner who killed hundreds of his patients, are shocking partly because they are so unusual. However, other cases illustrate that groups of professionals quite often fail to uphold their duties through a mixture of self-interest, incompetence and sheer indifference to the problems they encounter. A good illustration is the appalling suffering of patients at Mid Staffordshire NHS trust in the 2000s, which was caused by a whole range of individuals operating in professional jobs at various levels of the organization. Ultimately, after much campaigning over several years by relatives and a series of critical reports, a public inquiry was arranged to examine the problems at the hospital. The findings were damning.

The inquiry found significant problems at all levels of the trust. According to Robert Francis QC, chair of the public inquiry, managers were more interested in business pro-cesses than the care of patients and when things started to go wrong, complaints from families were simply ignored. Evidence was collected of nurses who abused patients in an atmosphere where such behaviour became normalized. The medical profession was also blamed for allowing failures to occur, resulting in unacceptable and inhumane treatment of patients. The inquiry was particularly critical of the senior management of the trust, several of whom received large financial payouts as the scale of the problems started to surface. The absurdity reached new heights when those in charge of the failings went on to secure highly paid positions in other health quangos, as widely reported in the press (Smith 2018). There was something clearly very wrong with the management and culture of the trust with many individual lives deeply affected by the tragedies that occurred at Stafford Hospital, but one is left wondering why the regulators of the NHS, the professional bodies and the individual professionals, over a period of several years at the hospital, failed to notice and take appropriate action earlier. As Robert Francis concluded, not only the Trust Board but the whole system failed in its duty to protect patients (HC 2013).

Obviously, throughout the world, professionals work hard every day to care for clients and patients, and when things do go wrong, many are prepared to put their duty to others before self-interest. Yet, it is clear from the above cases, and many others which could have been explored such as the financial crisis of 2008 , that those individuals who operate in the professions may not universally deserve the special respect their professional bodies claim. Additionally, as in the above cases, professional bodies seem to have been slow to protect the public from their practising members. I think it is fair to claim that despite the increasing number of occupations claiming the privileged status of a profession, there is probably more scepticism amongst the media and general public regarding the levels of trust our contemporary professions should enjoy. 


\section{What is a Profession?}

The three learned professions of medicine, law and the church were recognized for several hundred years as higher-level occupations, and by the late nineteenth century social reformers such as Annie Besant were acknowledging the prestige attached to these occupations. But it was not until the twentieth century that academics attempted systematically to study the professions. One of the earliest works was by the English academics Carr-Saunders and Wilson (1933). They attempted to examine the documentation of occupations that were typically considered professions; for example, lawyers, surveyors and pharmacists, with the aim of finding out what makes an occupation a profession. Although there are methodological weaknesses, since the researchers limit their investigation to documentation rather than empirical data from practitioners, there is nevertheless a clear conclusion that professions distinguish themselves principally through the use of ethical codes of conduct and a long period of 'prolonged and specialised training' (Carr-Saunders and Wilson 1933:491).

The above work acted as a foundation for other academics, particularly sociologists, to develop conceptual clarity around the idea of a profession. Millerson (1964) is a good example of how this work developed. He produced an in-depth study which examined the process of professionalization, i.e. the process which occupations go through to achieve professional status. He distilled the essential traits of a profession as:

\section{A profession involves the skill based on theoretical knowledge}

This skill requires training and knowledge

The professional must demonstrate competence bypassing a test

Integrity is maintained by an adherence to a code of conduct

The Service is for the public good

The profession is organised. (Millerson 1964:4)

We therefore now have a clearer understanding of what a profession is, and it is clear that ethical claims around codes of conduct and 'the public good' are central to the assertions of professional status across a range of occupations. An examination of contemporary professional association websites indicates that this is still true today. The Royal Institution of Chartered Surveyors is a good example and clearly sells the profession on the basis that RICS members are people one can trust. Their website states: 'All members must demonstrate that they: act with integrity; always provide a high standard of service; act in a way that promotes trust in the profession; treat others with respect; take responsibility' (RICS 2018). Additionally, RICS is a member of a global coalition of professional bodies who work to standardize professional ethics across the world, in this case the International Ethics Standards Coalition (IESC 2018).

Thus, we have professional bodies who promote their members as people of integrity and trust, alongside the increasing visibility of cases where professions seem to fail to uphold these standards. I believe that this is sometimes because although professional bodies insist that individuals are tested on their understanding of the respective codes at initial qualification, and have continuing professional development requirements to keep current, a deeper understanding of ethical reasoning is missing. It is one thing to be able to recite a list of ethical 'dos and don'ts' from a code of conduct and maybe apply them in simplified test paper scenarios: it is something else to ethically reason through dilemmas in the daily working environment. Ethical reasoning involves moving 
beyond mere intuition and code check-lists to something more informed, which involves a level of philosophical literacy that I claim is currently absent in many professionals.

\section{Philosophical Reasoning}

Imagine what would happen if the directors of Carillion, South Staffs NHS trust, or similar cases thought through their decisions while drawing in ideas from Kant, such as the categorical imperative? In the first formulation of the categorical imperative Kant states: 'I ought never to act except in such a way that I can also will my maxim should become a universal law' (Kant 1991: 67). If a financial director feels under pressure to post results to keep the rest of the board and the investors happy, it is understandable that the balance sheet will be presented as positively as the law allows. However, this pressure can be balanced by reasoning informed by the first formulation of the categorical imperative. Would a financial director rationally want others to distort their accounts to the point where they were legal but 'fantastical'; surely not, since no one would then have any reason to believe the accounts submitted of any firm. Therefore, we can see this action is morally dubious from a Kantian perspective.

An alternative formulation of Kant's categorical imperative states: 'Act in such a way that you always treat humanity, whether in your own person or in the person of any other, never simply as a means but always at the same time an end' (Kant 1991: 91). So in the case of directors who control employees' pension funds, even if the actions to divert money from pension funds to pay investors' dividends are within the law, it is surely treating the employees who are working for the company as simply a means to another end. Treating the workers as individuals, worthy of respect, is certainly inconsistent with the practice of syphoning off funds to protect pensions.

Clearly, the world of business is by its nature competitive, but it's wrong to pretend there are no rules. There are the rules of law, compliance with regulators, and also the assertions of professional bodies who claim special juris-diction over various functions, as discussed above. The problem arises when these conflict with competitive pressures and individual greed or even indifference. My argument is that codes are necessary, but they are not a sufficient condition for the ethical practice professional bodies claim. Ethical reasoning, as briefly shown above, requires philosophical literacy to help condition our intuitions. Building on the popular concept of scientific literacy, I will define philosophical literacy as 'understanding and applying concepts, theories and ideas from philosophy to personal, professional and civic contexts'.

\section{How to Increase Philosophical Literacy}

Although increasing philosophical literacy is important throughout life and particularly when people enter the professions, a general understanding needs to start at school.

This idea is often discussed within philosophy circles but seems to fall on the deaf ears of government, who seem to have an almost obsessive view regarding the importance of maths, English and science in the curriculum. I recently raised the question: 'do you think government does not support philosophy in schools because they believe it to be a useless subject, or because they think it's dangerous?' This was put to A. C. Grayling during a $Q$ and A session at Lincoln University. He thought it was the former: I'm not so sure. If politicians think philosophy is so useless, why do so 
many of them choose the well-trodden path to a degree in Politics, Philosophy and Economics at Oxford?

I think there are several areas of action that can progress philosophical literacy, which ultimately will lead to a more informed application of ethics in the professions. First, anybody interested in philosophy has an obligation to evangelize and spread the word to the whole population. Ultimately, in some respects, philosophy is the most useful subject because it helps us think more clearly and live better, more authentic lives. The tragedy is that the majority of people in our affluent western society probably go to their graves having no idea whether Bentham, Kant and Sartre are the latest pop stars or philosophers who could have changed their lives. A problem traditionally cited is that philosophers are seen as remote characters who spend their lives writing inaccessible journal papers, which have no relevance to the lives of the ordinary folk on the Clapham omnibus. Even if this is a genuine problem, I think things have changed over recent years. In the UK, the philosophers of our time, for example, Mary Warnock, Onora O'Neill, Alain De Botton, Simon Blackburn, Roger Crisp, A. C. Graying, Nigel Warburton, Stephen Law, Angie Hobbes, to name but a few, have been increasingly recognizable as great public philosophers. These are genuine public philosophers in the sense that they are changing people's lives through their public engagements and accessible writing. In short, they are getting more people to think philosophically. Some work as full-time academic professors of philosophy in universities: some do not. But the growth of the internet has given an increasing platform to these philosophers, for example through videos and pod-casts, which only twenty years ago would be almost unthinkable. Additionally, smartphone apps such as 'meetup' demonstrate that a growing number of people wish to spend an evening with others discussing philosophical issues.

I think there is a genuine hunger for philosophy in the population, particularly when that population understands what philosophy is about. A good start to increase philosophical literacy would be a school curriculum that included philosophy, which was clearly separated from religious studies. GCSEs and A levels in 'Religion and Ethics', for example, are probably of limited interest to many young, largely non-religious, school students. A new GCSE in philosophy, clearly differentiated from religious studies, would potentially be far more attractive, especially to those going on to study sciences and other so-called 'useful subjects', particularly if the independent thinking and critical evaluation aspects were emphasized. It will also help develop a pool of students who will be enthusiastic to study philosophy for non-instrumental reasons.

Beyond school, the philosophical literacy of non-philosophy undergraduates is also an area which has enormous potential for growth. Students studying degrees such as medicine, engineering, accountancy, business studies, economics and architecture would all benefit from a greater understanding of philosophical reasoning. Celebrated neuro-surgeon Henry Marsh has written on the profound dilemmas he faced as a brain surgeon with a precision that demonstrates an understanding of the human condition well beyond the medical (Marsh 2014). It is unsurprising to discover he graduated in philosophy before entering medical training.

Finally, lifelong education provides an opportunity for professionals to deepen their philosophical literacy beyond a superficial understanding of the code of conduct necessary to pass an entrance test or examination. Although there has been some growth in online and distance philosophy provision, this has been balanced by the enormous decline in Open University numbers owing to massive increases in part-time fees. This has meant that one of the most respected providers of philosophical lifelong learning is being terribly damaged, but hopefully not beyond repair. 
Although all members of the population would benefit from increasing their philosophical literacy, the purpose of this article was specifically to highlight those occupations that claim a special and privileged status in the world. The professions have an obligation to improve the ethical reasoning of their members, especially if they are to build trust and avoid some of the recent scandals discussed at the start of this article.

Andrew Knight PhD FRICS is Dean of Architecture, Design and the Built Environment at Nottingham Trent University. andrew.knight@ntu.ac.uk

\section{References}

Carr-Saunders, A. M. and Wilson, P. A. (1933) The Professions (Oxford: Clarendon Press).

IESC (2018) 'The International Ethics Standards Coalition' International Ethics Standards, ,https://iescoalition.org.[accessed 14 July 2018].

Kant, Immanuel (1991) The Moral Law, trans. H. J. Paton (London: Routledge).

Marsh, Henry (2014) Stories of Life, Death and Brain Surgery (London: Weidenfeld \& Nicolson).

Millerson, Geoffrey (1964) Qualifying Associations (London: Routledge \& Kegan Paul).

Parliament: The House of Commons [HC] (2013) Report of the Mid Staffordshire NHS Foundation Trust Public Inquiry (HC947) (London: The House of Commons).

Parliament: House of Commons [HC] (2018) Carillion, Report Together With Formal Minutes Relating to Report (HC 769)(London: House of Commons).

Smith, Rebecca (2018) 'Stafford Hospital Execs Land Highly-Paid Jobs', Telegraph.co.uk, ,https://www.telegraph.co.uk/news/health/news/5007652/Stafford-Hospitalexecs-land-higly-paid-jobs. html. [accessed 14 July 2018].

Royal Institution of Chartered Surveyors [RICS] (2018) 'Ethics and Professional Standards', Rics.org, ,https://www.rics.org/uk/regulation1/compliance1/ethics-professional-standards/. 